\title{
Complexity Analysis of Dynamic Cooperative Game Models for Supply Chain with the Remanufactured Products
}

\author{
Jianwei Chang ${ }^{1}$ and Liuwei Zhao $\mathbb{D}^{2}$ \\ ${ }^{1}$ School of Finance and Economics, Jiangsu University, Zhenjiang, Jiangsu 212013, China \\ ${ }^{2}$ Computational Experiment Center for Social Science, School of Management, Jiangsu University, Zhenjiang, Jiangsu 212013, China \\ Correspondence should be addressed to Liuwei Zhao; 136901672@qq.com
}

Received 2 April 2018; Revised 23 May 2018; Accepted 4 June 2018; Published 3 July 2018

Academic Editor: Lu Zhen

Copyright ( 2018 Jianwei Chang and Liuwei Zhao. This is an open access article distributed under the Creative Commons Attribution License, which permits unrestricted use, distribution, and reproduction in any medium, provided the original work is properly cited.

\begin{abstract}
This study focused on the supply chain within the remanufacturing production system, which is composed of one manufacturer and one retailer. In this case, the manufacturer is responsible for the production of new products and the remanufactured products. This system can be regarded as a coupling dynamics of the forward supply chain of Stackelberg game model. Based on the analysis, some dynamic phenomena such as bifurcation and chaos were found. Numerical simulations and the maximum Lyapunov exponent were therefore utilized to provide experimental evidence for the complicated behaviors of the system evolution. The findings of the study revealed that the equilibrium of the system can lose stability via flip bifurcation or Neimark-Sacker bifurcation and that time-delayed feedback control is appropriate for stabilizing the chaotic behaviors of the system.
\end{abstract}

\section{Introduction}

In recent years, numerous people are paying high attention to the environment and sustainable development. This accentuates the continuous development and advancement of mechanisms towards protecting and safeguarding the environment. Recycling and remanufacturing has therefore become a key tool by which many enterprises enhance their core competitiveness [1-3].

Economic and environmental sustainability contributes to the reduction in production cost and enhances the profits of enterprises; hence more enterprises are embracing the remanufactured product supply chain $[4,5]$. Sustainable recycling of resources has increasingly become the focus of attention by governments, enterprises, and society. At present, governments around the world through the legislative process are enacting policies to protect the ecological environment and safeguard the natural resources. New measures for energy conservation and emission reduction are constantly been rolled out by governments and key stakeholders. One of the key measures for energy conservation and emission reduction is remanufacturing. Remanufacturing has consequently been acknowledged for the superior benefits it offers. In comparison with other approaches, remanufacturing is more economically and environmentally sustainable; it reduces the cost of production for enterprises, increases the profits of enterprises, and offers several opportunities for more companies to join product remanufacturing [4].

In recent years, the competition strategy and power structure of the remanufacturing supply chain have further attracted widespread attention from relevant scholars. For instance, Majumder and Groenevelt studied the manufacturer's pricing and remanufacturing strategy facing remanufacturer competition [6]. Bulmus et al.'s research focuses not only on the competition between the original manufacturer and the remanufacturer on the product side, but also on the competition between the two in the product recycling market [7]. Adem et al. took into full consideration the impact of competition in quality and quantity between the original manufacturer and the remanufacturer on profits, consumer surplus, and total social welfare [8]. Gao Juhong et al. comprehensively studied the influence of different market power structures between manufacturers and retailers on the 
optimal decision-making and market performance of closedloop supply chains [9]. Cao Xiaogang and others established the Stackelberg game, manufacturer and retailer Stackelberg competition game model led by manufacturers, obtained the equilibrium solutions under different decision modes, and analyzed parameters such as consumer preference level, remanufacturing cost saving, and decision and profit impact [10].

The above research has greatly enriched the theory of remanufacturing supply chain competition and optimization design. Under certain market conditions, the supply chain system can also be seen as a game between manufacturers and retailers. Therefore, the system dynamics method is an important research perspective. These researches enrich the competition theory and optimal design of the remanufacturing supply chain greatly. These researches augment the competition theory and optimal design of the remanufacturing supply chain greatly. Under certain market conditions, the supply chain system can be regarded as a game between manufacturers and retailers, so system dynamics is an important perspective of research. Vlachos et al. gave a simulation model based on the principles of the system dynamics methodology to evaluate alternative longterm capacity planning policies using total supply chain profit as a measure of policy effectiveness [11]. Hammond and Beullens expanded the work dealing with oligopolistic supply chains to the field of supply chain. They elucidated a supply chain network model consisting of manufacturers and consumer markets with perfect information [12]. They pointed out that supply chain equilibrium occurred when all players agreed on volumes shipped and prices charged. Chen and Chang dealt with the strategic issue of supply chain with remanufacturing by developing analytic models under cooperative and competitive settings to investigate the conditions under which an original equipment manufacturer may take a cooperative approach by participating in remanufacturing [13]. Their analyses revealed that the strategic decisions depended critically on the costs of remanufacturing and the competition intensity. Guo and Ma employed the numerical simulation, the complex dynamic phenomena, such as bifurcations, chaos, and continuous power spectrum, in analyzing the complexity of retailer collecting and selling in closed-loop supply chain [14]. Wang Wenbin et al. built a variational inequality optimization model to analyze the impact of two strategies (government penalty for producers and government subsidy for recyclers) on the closed-loop supply chain. Their findings revealed that government subsidies for recyclers can improve the total recovery as well as increase the demands for new and old materials [15]. Jin Changfei et al. built a Stackelberg model of game between producers and retailers to analyze the sales volumes of green products and ordinary products in the following circumstances, respectively: producers not participating in recycling and remanufacturing; producers participating in recycling and remanufacturing; the government adopting an incentive strategy based on total recovery subsidy; and the government adopting an incentive strategy based on recovery rate subsidy [16]. Chang Xiangyun et al. introduced a system dynamic model in analyzing the impact of carbon tax constraint and subsidy incentive on the auto parts remanufacturing decision-making and proposed that the combination of tax policy and subsidy incentive is more conducive to higher carbon reduction efficiency and higher economic efficiency of auto parts remanufacturing [17]. Several other researchers such as Guide and Van Wassenhove [18], Hatcher et al. [19], and Souza [20] have extensively reviewed literature covering all aspects of remanufacturing. Regarding research on remanufacturing and subsidies, Tukker et al. [21] and Vercraene et al. [22] studied the impact of demand uncertainty on government subsidies for green technology adoption and appraised trade-in remanufacturing with strategic customer behavior and government subsidies [23-25], etc.

From the extant literature, it is lucidly clear that most researchers that studied remanufacturing supply chains system employed models that consider only one aspect of the remanufacturing supply chain. There is therefore the urgent need to explore newer models to discuss the impact of different pricing strategies on the stability of supply chain systems. This current paper therefore extends the frontlines of recent research as it proposes a noncooperative game model approach in which manufacturers manufacture new products and remanufactured products at the same time. Through numerical simulation, the dynamics of the supply chain and the influence of decision parameters on the complex nonlinear dynamic behavior are analyzed.

This rest of the paper is organized as follows. In Section 2, the assumptions and notations are described. In Section 3, we present the Stackelberg game model while using numerical simulations to analyze its dynamic phenomena. In Section 4, the time-delayed feedback control is used to stabilize the chaotic behaviors of the system. Finally, conclusions are drawn in Section 5.

\section{Model Assumptions and Notations}

2.1. Assumptions. The following assumptions are made to develop the model for the supply chain system.

(i) The supply chain consists of a manufacturer and a retailer as shown in Figure 1. In this case, the manufacturer engages in the production of new products and remanufactured products. The retailer sells new products and remanufactured products to consumers. The supply chain system is an integration of the forward supply chain. The manufacturer and the retailer are independent decisionmakers, and their goal is to maximize returns in discrete time period as shown in Figure 1.

(ii) The demand for new products in the market is greater than the market supply for new products, so remanufactured products occupy a certain market share.

(iii) There is no difference between remanufactured products and new products which are made of raw materials, but the cost of remanufactured products and the accessories in the production process are lesser than those of new products, so they are listed in the market, forming a core competitiveness advantage.

(iv) Consumers have personal preference for purchasing new products or remanufacturing products. 


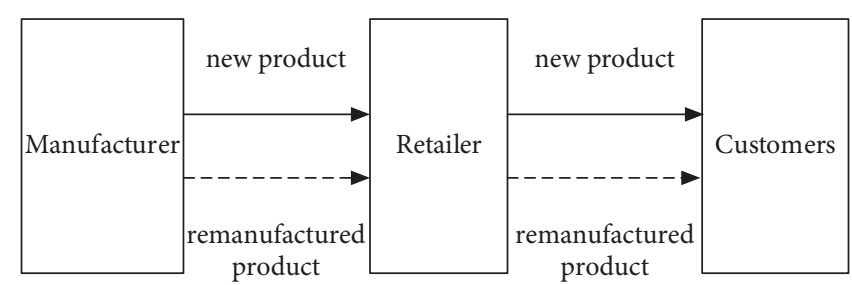

FIGURE 1: The supply chain system.

2.2. Notations. We considered the demand for products in the market as a linear function of product price. The demand function of new products manufactured with raw materials is computed as $D_{n}=a_{1}-b_{1} p_{R n}$; the demand function of remanufactured products is computed as $D_{r}=a_{2}-b_{2} p_{R r}$, where $a_{i}>0(i=1,2)$ is the market scale and $b_{i}>0(i=$ $1,2)$ is the price sensitivity of consumers. The parameter $b_{i}$ is determined by the property of the products, such as similar degree. In general, the higher (lower) the degree of substitutability, the higher (lower) the value of $b_{i}$. Similarly the importance of goods determines the value of $b_{i}$. The $b_{i}$ is lower for basic necessities of life, while the value of $b_{i}$ is higher for luxury goods that are nonessential; and as for the adjustment time of consumers to demand, in general, the shorter (longer) the adjustment time, the lower (higher) the value of $b_{i}$.

The wholesale price of the manufacturer, wholesaling to the retailer, is defined as the cost of the remanufactured products and the new products manufactured with raw materials. This is computed mathematically as follows: $p_{n}(t)=p_{r}(t)(1+$ $\left.k_{n}\right)$.

The retailer's unit price for selling the new products and the remanufactured products are estimated, respectively, as follows: $p_{R n}(t)=p_{n}(t)\left(1+k_{1}\right)$ and $p_{R r}(t)=p_{r}(t)\left(1+k_{2}\right)$.

Hence, the profit function of the manufacturer is computed as follows:

$$
\begin{aligned}
\pi_{m}(t) & =\pi_{m n}(t)+\pi_{m r}(t) \\
& =\left[p_{n}(t)-c_{n}\right] D_{n}+\left[p_{r}(t)-c_{r}\right] D_{r} .
\end{aligned}
$$

The profit function of the retailer is as follows:

$$
\begin{aligned}
\pi_{R}(t) & =\pi_{R n}(t)+\pi_{R r}(t) \\
& =\left[p_{R n}(t)-p_{n}(t)\right] D_{r}+\left[p_{R r}(t)-p_{r}(t)\right] D_{r} .
\end{aligned}
$$

Consequently, the overall profit of the supply chain is computed as follows:

$$
\pi(t)=\pi_{m}(t)+\pi_{R}(t) .
$$

The manufacturer chooses the remanufactured products price $p_{r}(t)$ and profitability $k_{n}$ as decision variables, while the retailer chooses selling the new products at a profit $k_{1}$ and the remanufactured products at a profit $k_{2}$. The three profit functions are expressed as follows:

$$
\begin{aligned}
& \pi_{m}(t)=\left(\left(1+k_{n}\right) p_{r}(t)-c_{n}\right)\left(a_{1}\right. \\
& \left.\quad-b_{1}\left(1+k_{1}\right)\left(1+k_{n}\right) p_{r}(t)\right)+\left(p_{r}(t)-c_{r}\right)\left(a_{2}\right. \\
& \left.\quad-b_{2} p_{r}(t)\left(1+k_{2}\right)\right)
\end{aligned}
$$

$$
\begin{aligned}
& \pi_{R}(t)=p_{r}(t) \\
& \cdot\left(\left(1+k_{1}\right)\left(1+k_{n}\right)\left(a_{1}-b_{1}\left(1+k_{1}\right)\left(1+k_{n}\right) p_{r}(t)\right)\right. \\
& \left.\quad-k_{2}\left(b_{2}\left(1+k_{2}\right) p_{r}(t)-a_{2}\right)\right) \\
& \pi(t)=p_{r}(t) \\
& \cdot\left(b_{1}\left(1+k_{1}\right)\left(1+k_{n}\right)\left(c_{n}+k_{1}\left(1+k_{n}\right) p_{r}(t)\right)\right. \\
& \left.+b_{2}\left(1+k_{2}\right)\left(c_{r}+\left(k_{2}-1\right) p_{r}(t)\right)\right)-a_{2}\left(c_{r}\right. \\
& \left.+\left(k_{2}-1\right) p_{r}(t)\right)-a_{1}\left(c_{n}+k_{1}\left(1+k_{n}\right) p_{r}(t)\right) .
\end{aligned}
$$

\section{Stackelberg Game Model}

Suppose that, in the supply chain, the manufacturer and the retailer are all in pursuit of maximum profits and make decisions independently as independent subjects where the manufacturer is the leader and the retailer is the follower. Then this relationship implies the dominance of the manufacturer over the retailer. They form a Stackelberg game, and the game equilibrium is referred to as the Stackelberg Equilibrium [26]. In this game, the manufacturer makes decisions for the determination of the wholesale price of the remanufactured products and profitability according to the market information. The retailer, on the other hand, makes decisions of the profitability of the new products and the remanufactured products according to the decision-making of the manufacturer.

3.1. Model and Analysis. The retailer's selling of the new products and the remanufactured products profitability are decided by solving the following optimization problem:

$$
\left(k_{1}, k_{2}\right)=\arg \max \pi_{R} .
$$

This can be adduced by the first-order conditions of $\pi_{R}$ :

$$
\begin{aligned}
& \frac{\partial \pi_{R}(t)}{\partial k_{1}} \\
& \quad=\left(1+k_{n}\right) p_{r}(t)\left(a_{1}-2 b_{1}\left(1+k_{1}\right)\left(1+k_{n}\right) p_{r}(t)\right) \\
& \frac{\partial \pi_{R}(t)}{\partial k_{2}}=p_{r}(t)\left(a_{2}-b_{2}\left(1+2 k_{2}\right) p_{r}(t)\right) .
\end{aligned}
$$


The retailer's best reply functions is derived by solving (6) as follows:

$$
\begin{aligned}
& k_{1}=\frac{a_{1}-2 b_{1} p_{r}(t)-2 b_{1} k_{n} p_{r}(t)}{2 b_{1}\left(1+k_{n}\right) p_{r}(t)} \\
& k_{2}=\frac{a_{2}-b_{2} p_{r}(t)}{2 b_{2} p_{r}(t)} .
\end{aligned}
$$

Similarly, we can get the manufacturer's marginal profit as follows:

$$
\begin{aligned}
& \frac{\partial \pi_{m}(t)}{\partial p_{r}(t)} \\
& \quad=a_{2}+b_{2}\left(1+k_{2}\right)\left(c_{r}-p_{r}(t)\right)-b_{2}\left(1+k_{2}\right) p_{r}(t) \\
& \quad-b_{1}\left(1+k_{1}\right)\left(1+k_{n}\right)\left(\left(1+k_{n}\right) p_{r}(t)-c_{n}\right) \\
& \quad+\left(1+k_{n}\right)\left(a_{1}-b_{1}\left(1+k_{1}\right)\left(1+k_{n}\right) p_{r}(t)\right) \\
& \frac{\partial \pi_{m}(t)}{\partial k_{n}} \\
& \quad=p_{r}(t)\left(a_{1}+b_{1}\left(1+k_{1}\right)\left(c_{n}-2\left(1+k_{n}\right) p_{r}(t)\right)\right) .
\end{aligned}
$$

Considering the fact that agents of the manufacturer can never get the whole market information, their decisions are considered not completely rational. The managers always hope to gain more profit through the active managerial behavior. This paper will therefore adjust the remanufactured products price $p_{r}(t+1)$ and the profitability $k_{n}(t+1)$ on the bases of the marginal profits. Accordingly, the dynamic supply chain system is constructed as follows:

$$
\begin{aligned}
& k_{1}(t)=\frac{a_{1}-2 b_{1} p_{r}(t)-2 b_{1} k_{n}(t) p_{r}(t)}{2 b_{1}\left(1+k_{n}(t)\right) p_{r}(t)} \\
& k_{2}(t)=\frac{a_{2}-b_{2} p_{r}(t)}{2 b_{2} p_{r}(t)} \\
& p_{r}(t+1)=p_{r}(t)+\alpha_{1} p_{r}(t)\left(a_{2}+b_{2}\left(1+k_{2}(t)\right)\right. \\
& \quad \cdot\left(c_{r}-p_{r}(t)\right)-b_{2}\left(1+k_{2}(t)\right) p_{r}(t)-b_{1}\left(1+k_{1}(t)\right) \\
& \quad \cdot\left(1+k_{n}(t)\right)\left(\left(1+k_{n}(t)\right) p_{r}(t)-c_{n}\right)+\left(1+k_{n}(t)\right) \\
& \left.\quad \cdot\left(a_{1}-b_{1}\left(1+k_{1}(t)\right)\left(1+k_{n}(t)\right) p_{r}(t)\right)\right) \\
& k_{n}(t+1)=k_{n}(t)+\alpha_{2} k_{n}(t)\left(p _ { r } ( t ) \left(a_{1}+b_{1}\left(1+k_{1}(t)\right)\right.\right. \\
& \left.\quad \cdot\left(c_{n}-2\left(1+k_{n}(t)\right) p_{r}(t)\right)\right),
\end{aligned}
$$

where $\alpha_{i}>0(i=1,2)$ are the profit modification speed parameter, which reflect the company active managerial behavior.

3.2. Numerical Simulation. Our study sets the following parameters: $a_{1}=15 ; a_{2}=10 ; b_{1}=1.2 ; b_{2}=1 ; c_{n}=4 ; c_{r}=3$ and the initial values as $p_{r}(0)=5 ; k_{n}(0)=0.4$ in the system as shown in (9).

The influence of decision parameters to the supply chain system is shown in (9). Figures 2 and 3, respectively, show the bifurcation diagrams and the largest Lyapunov exponent plot of the supply chain system with $\alpha_{2}=0.1$ and $\alpha_{1}$ varying from 0 to 0.7 . We can conclude that the supply chain system is stable when $\alpha_{1}<0.435$. When $\alpha_{1}=0.435$, the supply chain system (9) causes the first bifurcation, $\alpha_{1}<0.538$ causes the second bifurcation, and the equilibrium of the supply chain system can lose stability via flip bifurcation and gradually enter the Neimark-Sacker bifurcation and chaotic state. The influences of $\alpha_{1}$ on profits of the manufacturer, retailer, and supply chain are shown in Figures 2(h), 2(i), and 2(j). In stable state, the profits of the manufacturer, the retailer, and supply chain are, respectively, 38.5, 30.02, and 68.52. The retailer's unit selling price for the new products and the remanufactured products price are shown in Figures 2(f) and 2(g). The variation of largest Lyapunov exponent is closely related to the change of the price adjustment rate of remanufactured products $\left(\alpha_{1}\right)$, which can be seen in Figure 3. This figure proves that when the price adjustment rate of remanufactured products $\left(\alpha_{1}\right)$ changes, the stability of the supply chain system becomes unstable, and the characteristics of mixed dynamics after bifurcation evolve.

Figure 4 denotes the cycle and chaotic diagram of the supply chain system with the adjustment speeds $\alpha_{1}, \alpha_{2}$ at the same time change. The equivalent period graph is shown in Figure 4(a). In the figure, from the lower-left corner, the district of different color depth converges once in 1 period, 2 periods, 4 periods, and 8 periods, which is made of parameters $\left(\alpha_{1}, \alpha_{2}\right)$. The economic meaning of $p$ period is that the parameter randomly chooses values in the point set, as the manufacturer chooses one initial remanufactured products price and profitability; after limited time games, the remanufactured products prices represent the periodicity changing of $p$, which is $M_{i}^{p}\left(p_{r}^{t_{0}}, k_{n}^{t_{0}}\right)=p_{i}^{t_{0}}, M_{i}^{k}\left(p_{r}^{t_{0}}, k_{n}^{t_{0}}\right) \neq$ $p_{i}^{t_{0}}, i=1,2$. All random integers are set up for $k<p$. $t_{0}$ represents arbitrary integer greater than random natural number; $M_{i}$ represents mapping in the system (9). The green district at the top right corner through iteration makes parameters on the value of enterprise production strategy become negative, which is also referred to as nonfeasible parameter set, from the path of parameter set. It describes the collapse of quality cost and profit system evolution. Based on Sarkovskii periodic orbit theorem, period 1, period 2, and period 4 all account for approximately $84.6 \%$. It can be inferred that the appeal of low cycle track has high possibility in the quality cost and profit dynamic evolution system.

In chaotic map, Figure 4(b), the dark area represents the chaotic state in the model of largest Lyapunov index meaning. It does not consider the fact that the production has negative value situation. It revealed that $15.6 \%$ is chaotic. This implies that the periodic phenomena are more common, also suitable for the realistic economic behavior. When $\alpha_{1}, \alpha_{2}$ increase to the certain degree, it has chaotic phenomenon. Thus, when enterprise makes production decision, the speed of production adjustment becomes faster; the market responding speed becomes faster, making the market become unstable. It has many different paths from period state to chaotic state as shown in Figure 4. Figure 4 fully explains the complexity of system evolution and the chaotic phenomenon. 


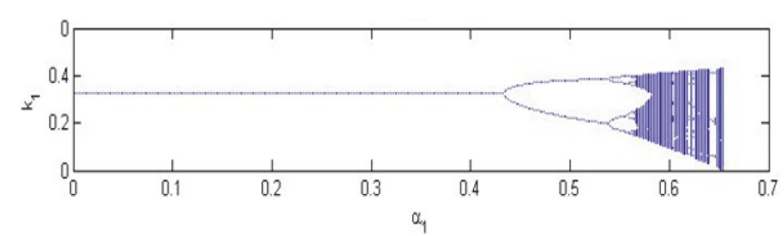

(a)

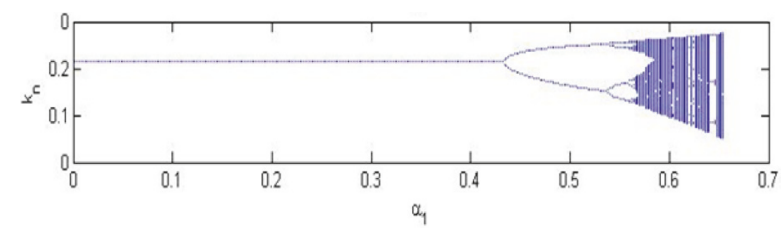

(c)

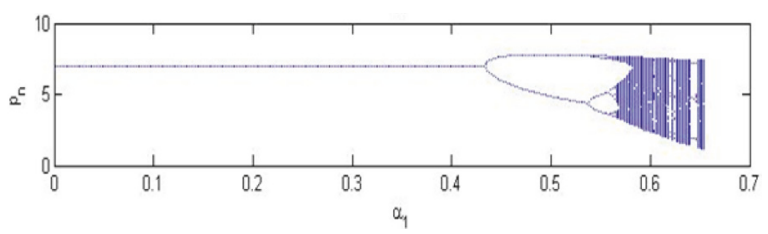

(e)

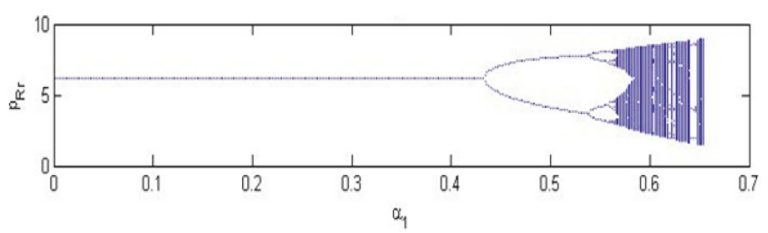

(g)

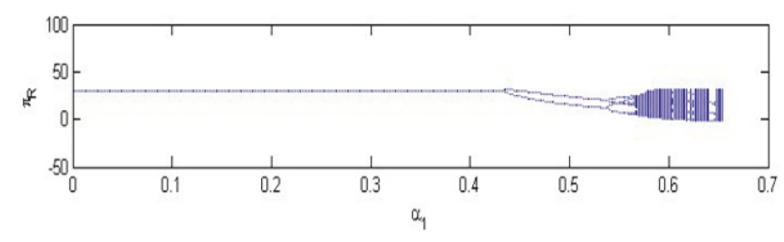

(i)

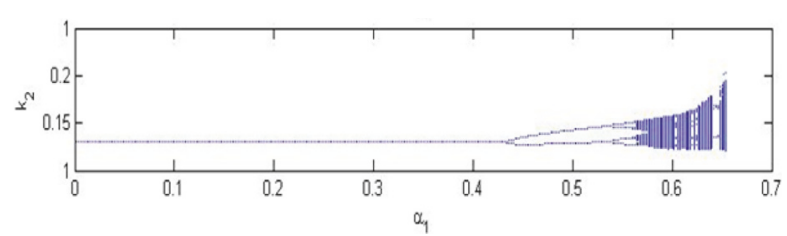

(b)

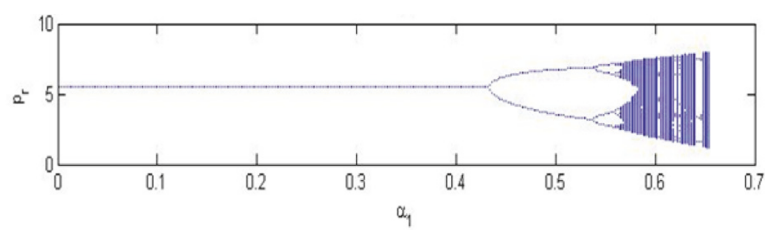

(d)

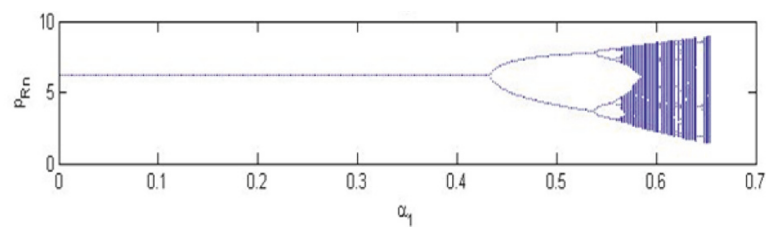

(f)

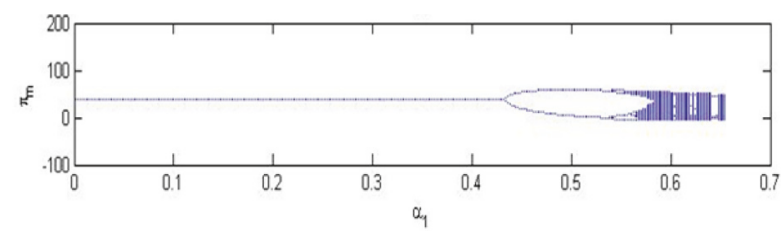

(h)

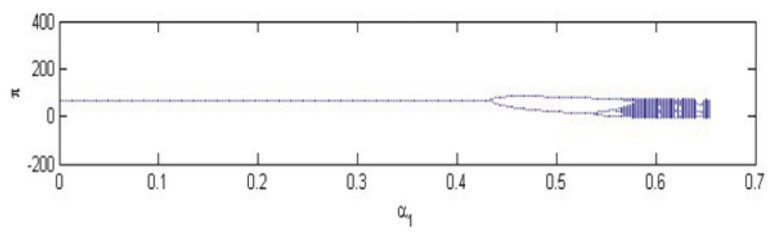

(j)

FIGURE 2: Bifurcation diagrams of the supply chain system (9) with the adjustment speed $\alpha_{1}$.

The influence of initial state on the supply chain system is shown in (9).

Figure 5 reveals the sensitive dependence for the dynamic system on initial values. The sensitivity of system (when loosing stability) to the manufacturer's initial remanufactured products price $p_{r}$ is taken as 5 and 5.0001, and small changes of the initial conditions can cause the observed large changes of the system, which is sensitive to initial states.

\section{Chaos Control}

From the numerical simulations, the adjustment rate and the weight coefficient had great influence on the stability of system (9). If the model parameters fail to locate into the stable region required, the behaviors of the dynamics will be much complicated. In a real economic system, chaos is undesirable and unwarranted. There is therefore the need to avoid or control chaos so that the dynamic system would work favorably. In this section, our study introduced the timedelayed feedback control $[27,28]$ to control system chaos. We modified the first equation of system (9) by intercalating a controller $K_{1}\left(p_{r}(t)-p_{r}(t+1)\right)$ and $K_{2}\left(k_{n}(t)-k_{n}(t+1)\right)$ as a small perturbation, where $K_{i}>0(i=1,2)$ is a controlling coefficient. The controlled system is computed in (10) as follows:

$$
\begin{aligned}
& k_{1}(t)=\frac{a_{1}-2 b_{1} p_{r}(t)-2 b_{1} k_{n}(t) p_{r}(t)}{2 b_{1}\left(1+k_{n}(t)\right) p_{r}(t)} \\
& k_{2}(t)=\frac{a_{2}-b_{2} p_{r}(t)}{2 b_{2} p_{r}(t)} \\
& p_{r}(t+1)=p_{r}(t)+\alpha p_{r}(t)\left(a_{2}+b_{2}\left(1+k_{2}(t)\right)\right. \\
& \quad \cdot\left(c_{r}-p_{r}(t)\right)-b_{2}\left(1+k_{2}(t)\right) p_{r}(t) \\
& \quad-b_{1}\left(1+k_{1}(t)\right)\left(1+k_{n}(t)\right)\left(\left(1+k_{n}(t)\right) p_{r}(t)-c_{n}\right)
\end{aligned}
$$




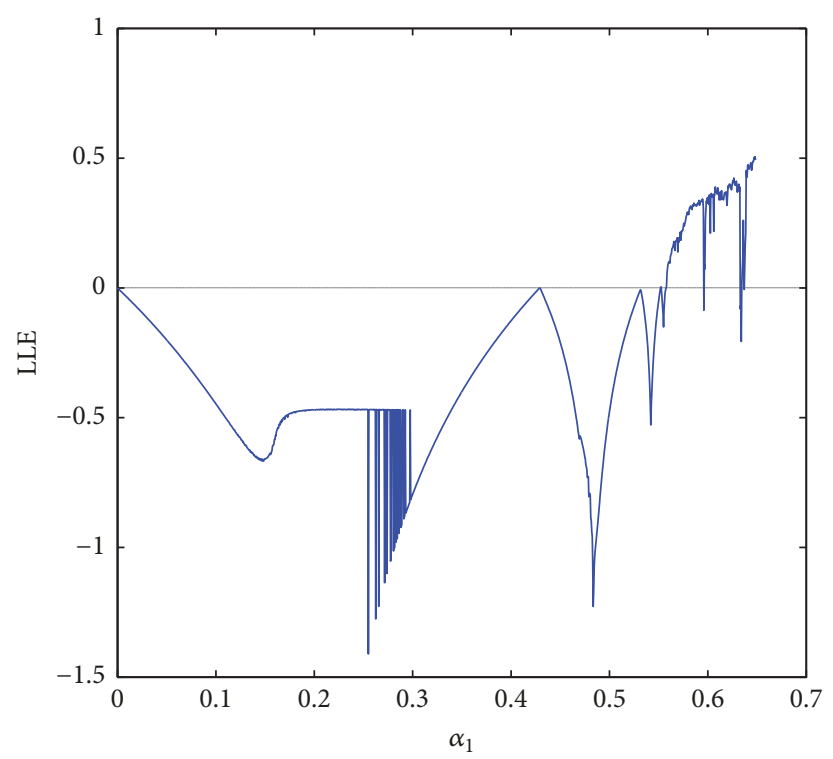

FIGURE 3: The largest Lyapunov exponent (LLE) plot of the supply chain system (10) with the adjustment speed $\alpha_{1}$.

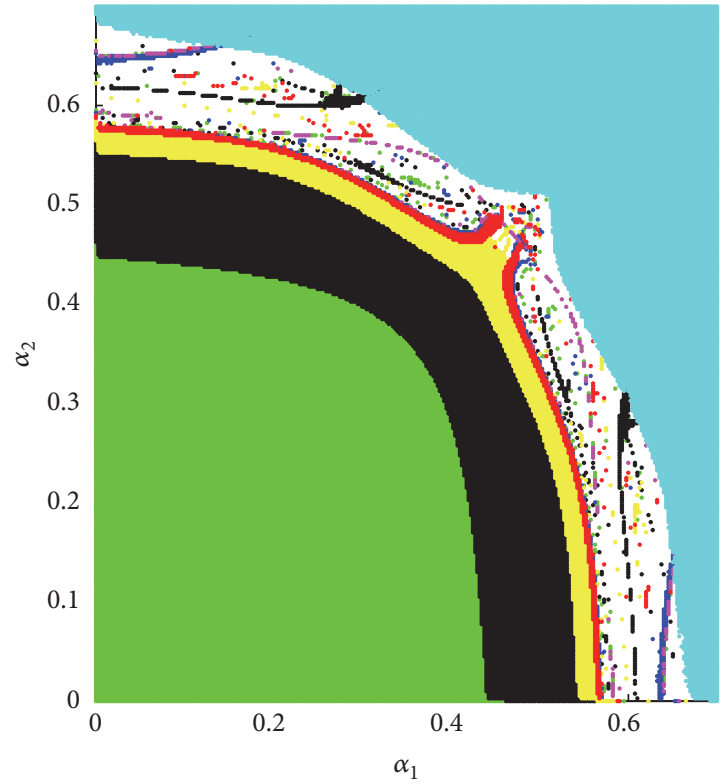

(a) Cycle diagram

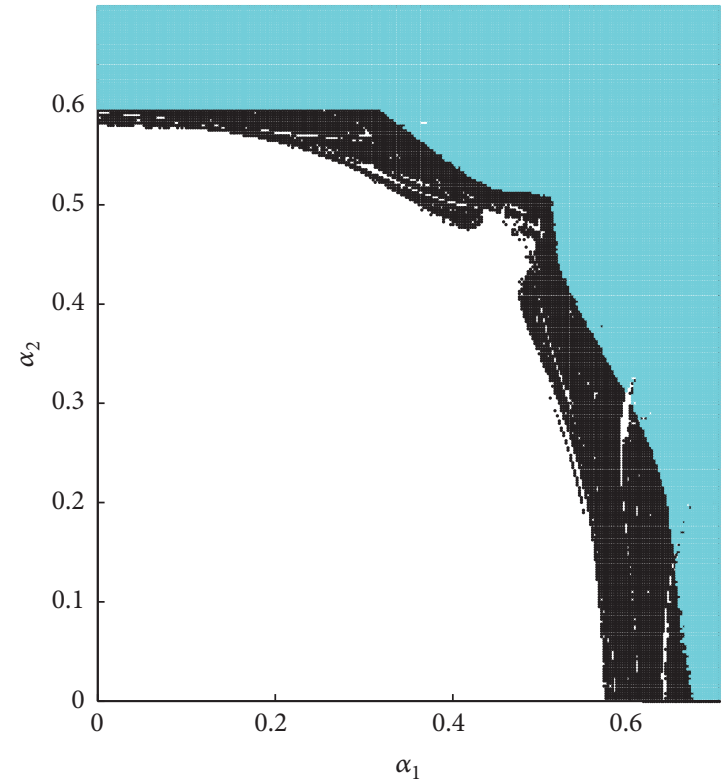

(b) Chaotic diagram

FIGURE 4: Cycle diagram and chaotic diagram of the system with the adjustment speeds $\alpha_{1}, \alpha_{2}$ at the same time.

$$
\begin{aligned}
&+\left(1+k_{n}(t)\right) \\
&\left.\cdot\left(a_{1}-b_{1}\left(1+k_{1}(t)\right)\left(1+k_{n}(t)\right) p_{r}(t)\right)\right) \\
&+ K_{1}\left(p_{r}(t)-p_{r}(t+1)\right) \\
& k_{n}(t+1)=k_{n}(t)+\beta k_{n}(t)\left(p _ { r } ( t ) \left(a_{1}+b_{1}\left(1+k_{1}(t)\right)\right.\right. \\
&\left.\quad \cdot\left(c_{n}-2\left(1+k_{n}(t)\right) p_{r}(t)\right)\right)+K_{2}\left(k_{n}(t)\right. \\
&\left.-k_{n}(t+1)\right) .
\end{aligned}
$$
same equilibriums as system (9) and it takes the following equivalent form:

$$
\begin{aligned}
& k_{1}(t)=\frac{a_{1}-2 b_{1} p_{r}(t)-2 b_{1} k_{n}(t) p_{r}(t)}{2 b_{1}\left(1+k_{n}(t)\right) p_{r}(t)} \\
& k_{2}(t)=\frac{a_{2}-b_{2} p_{r}(t)}{2 b_{2} p_{r}(t)} \\
& p_{r}(t+1)=p_{r}(t)+\frac{\alpha_{1} p_{r}(t)}{1+K_{1}}\left(a_{2}+b_{2}\left(1+k_{2}(t)\right)\right.
\end{aligned}
$$




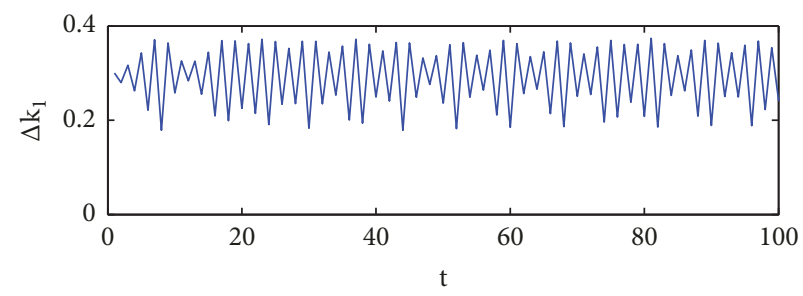

(a)

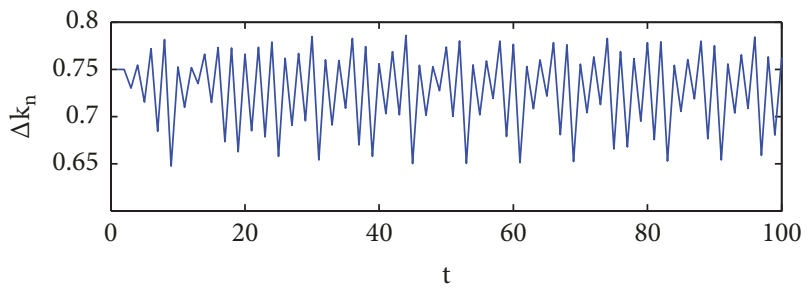

(c)

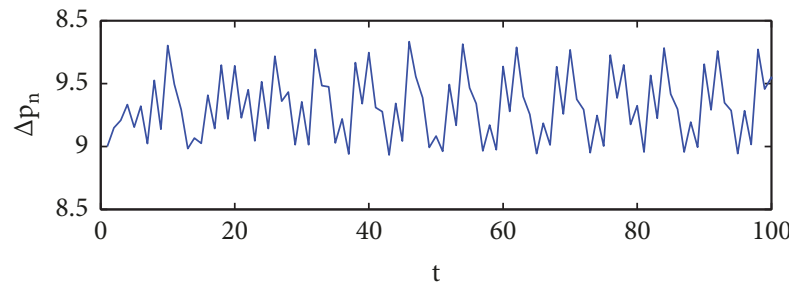

(e)

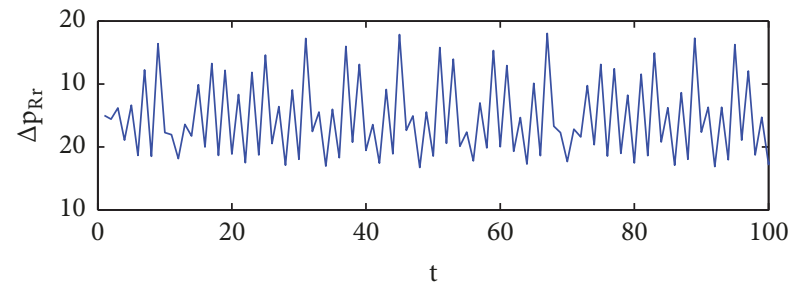

(g)

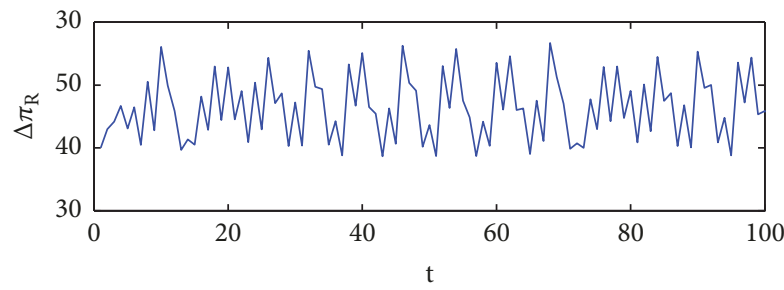

(i)

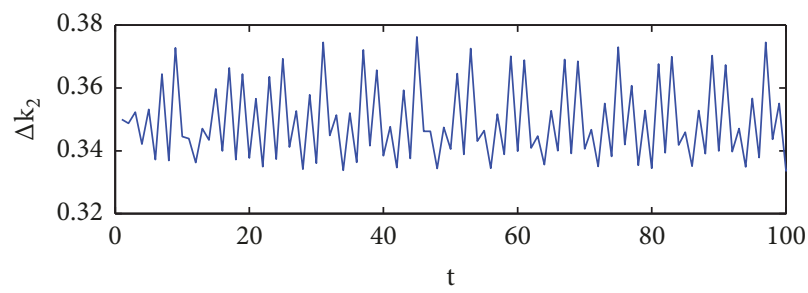

(b)

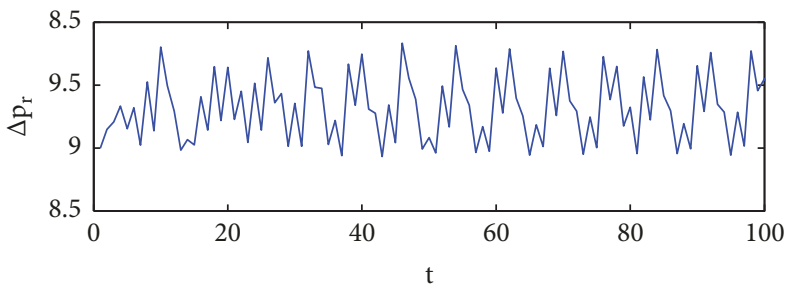

(d)

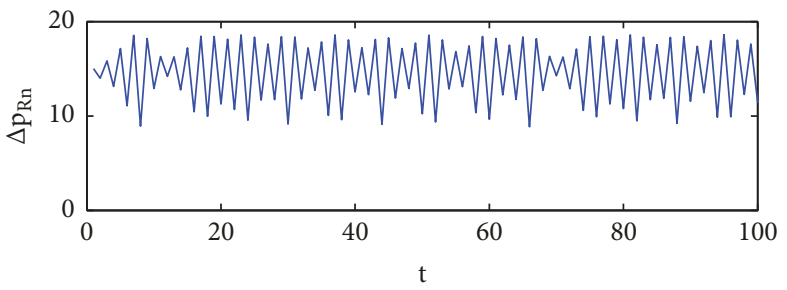

(f)

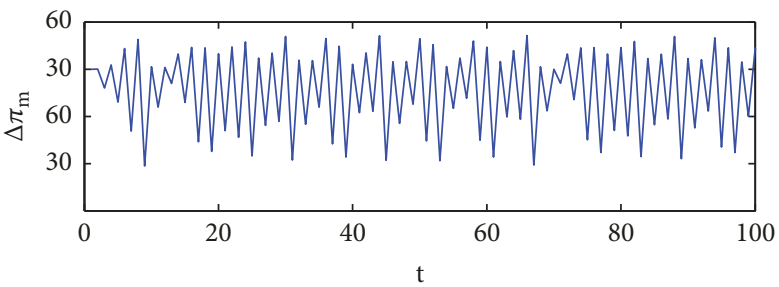

(h)

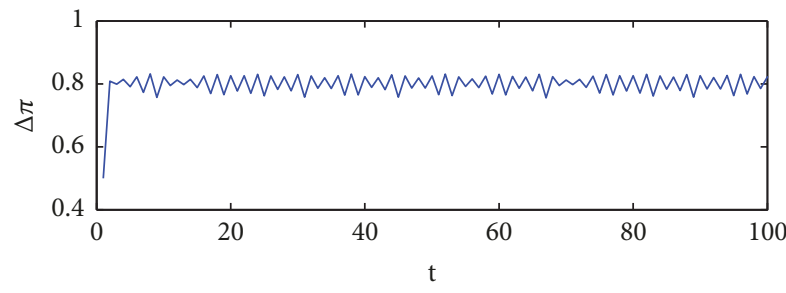

(j)

Figure 5: Sensitive dependence for the dynamical system (11) on initial conditions.

$$
\begin{aligned}
& \quad \cdot\left(c_{r}-p_{r}(t)\right)-b_{2}\left(1+k_{2}(t)\right) p_{r}(t) \\
& -b_{1}\left(1+k_{1}(t)\right)\left(1+k_{n}(t)\right)\left(\left(1+k_{n}(t)\right) p_{r}(t)-c_{n}\right) \\
& +\left(1+k_{n}(t)\right) \\
& \left.\quad \cdot\left(a_{1}-b_{1}\left(1+k_{1}(t)\right)\left(1+k_{n}(t)\right) p_{r}(t)\right)\right) \\
& k_{n}(t+1)=k_{n}(t)+\frac{\alpha_{2} k_{n}(t)}{1+K_{2}}\left(p _ { r } ( t ) \left(a_{1}\right.\right. \\
& \left.\quad+b_{1}\left(1+k_{1}(t)\right)\left(c_{n}-2\left(1+k_{n}(t)\right) p_{r}(t)\right)\right) .
\end{aligned}
$$

In Figure 6, we set some conditions. For instance when $K_{2}=0.3$, it is obviously observed that with the control coefficient $K_{1}$ increasing, the supply chain system gradually gets out of chaos and periodic windows and achieves stability when $K_{1}>0.0817$. The variation of largest Lyapunov exponent is closely related to the change of the control coefficient $\left(K_{1}\right)$, as shown in Figure 7. This figure further confirmed that when the control coefficient changes, the instability of the supply chain system becomes stable, and the characteristics of stable evolution after the doublecycled bifurcation evolve. We can also discuss the system 


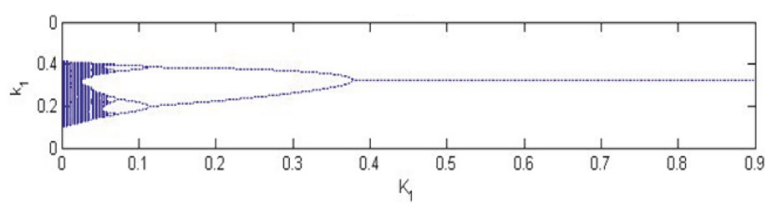

(a)

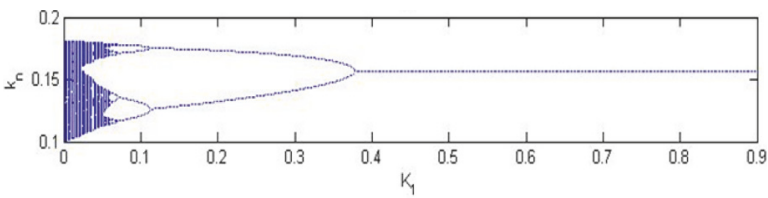

(c)

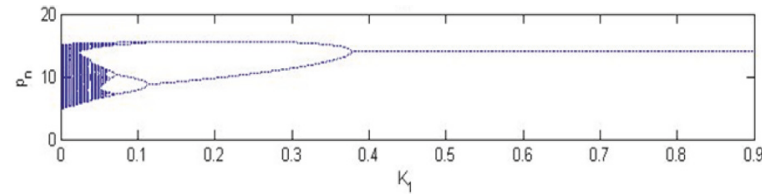

(e)

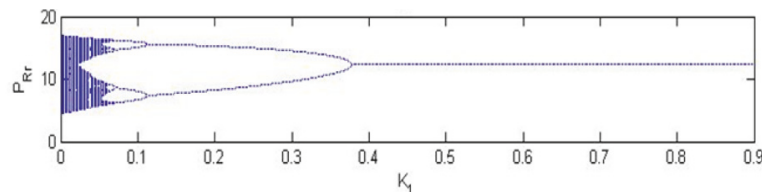

(g)

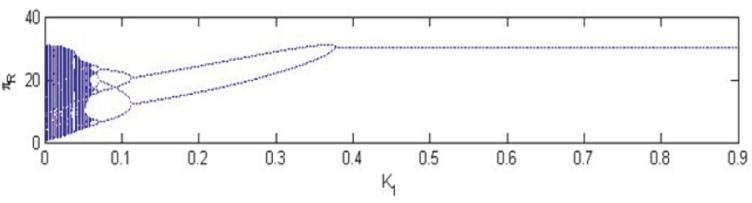

(i)

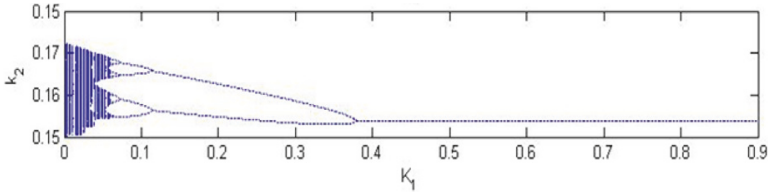

(b)

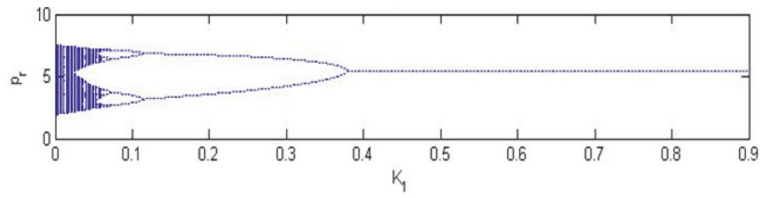

(d)

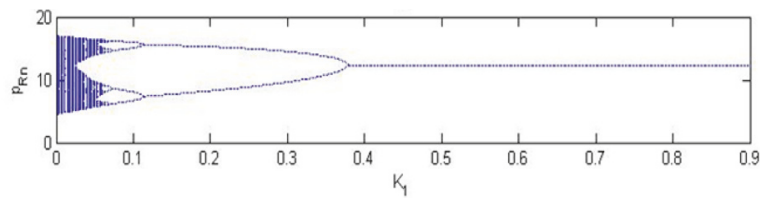

(f)

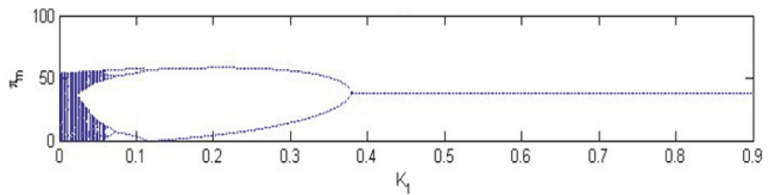

(h)

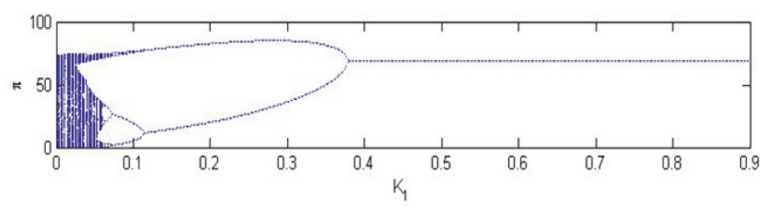

(j)

FiguRE 6: Bifurcation diagrams and the maximum Lyapunov exponent of system (11) with the controlling factor $K_{1}$.

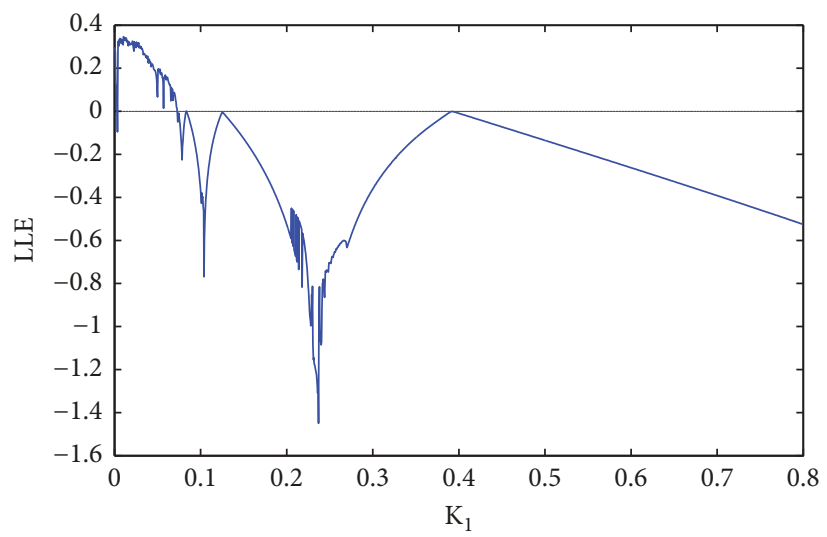

Figure 7: The largest Lyapunov exponent (LLE) plot of the supply chain system (10) with the controlling factor $K_{1}$.

stability of the controlled system from the view of the stability region in the two-dimension $K_{1}, K_{2}$-plane. Thus, the controlled system will be locally asymptotically stable provided that $K_{1}$ and $K_{2}$ take their values in the plotted region. Figure 8 (a) exhibits the cycle diagram whereas
Figure 8(b) depicts the chaotic diagram. By comparing Figures 4(a) and 4(b), we observed that the stability of the supply chain system is significantly enhanced after the implementation of the control system. We can therefore vehemently avow that the supply chain system chaos 


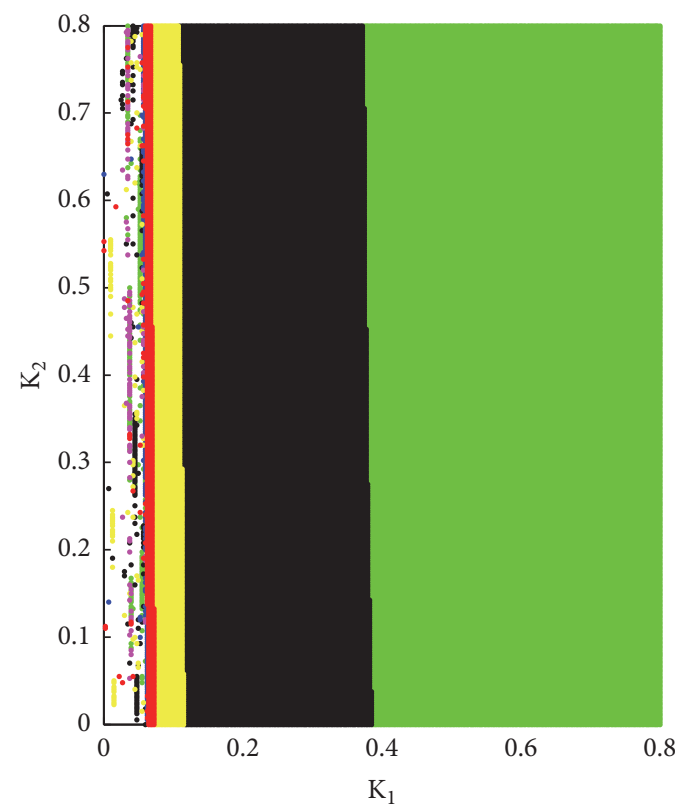

(a) Cycle diagram

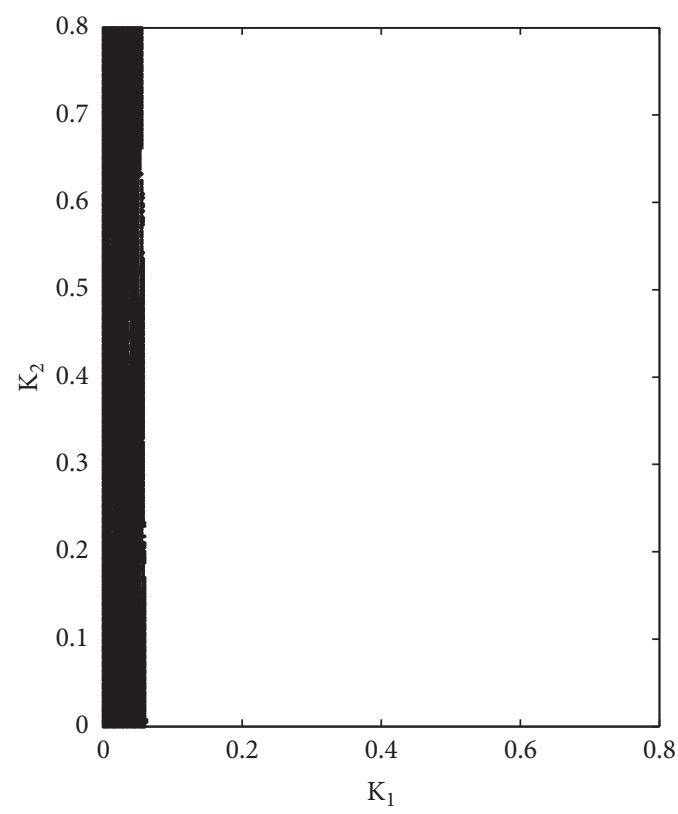

(b) Chaotic diagram

Figure 8: Cycle diagram and chaotic diagram of the system with the adjustment speeds $K_{1}, K_{2}$ at the same time.

is effectively controlled after employing feedback control approach.

\section{Conclusion}

This study investigated the supply chain in which manufacturers manufacture new products and remanufacture products at the same time using a noncooperative game model approach. The forward supply chain of Stackelberg game model was augmented and developed further for the analysis. The complexity of the models was investigated by simulation. Numerical simulations and the Maximum Lyapunov exponent were used to provide experimental evidence for the complicated evolution behaviors of the supply chain system. Findings of our study revealed that parameters play important role in the stability of the supply chain systems based on analyses of dynamical behaviors of the established game models. Moreover, the time-delayed feedback is a crucial control mechanism suitable for stabilizing the chaotic behaviors of the dynamic systems. The time-delayed feedback demonstrated that the chaotic behavior of the system can be controlled.

The study provided in-depth knowledge on supply chain mechanism within the remanufactured products-composed of one manufacturer and one retailer. This study will therefore serve as a useful guide for policy-makers, supply chain managers, and decision-makers for the implementation of strategic decisions.

\section{Data Availability}

The numerical simulations data used to support the findings of this study were supplied by Liuwei Zhao under license and so cannot be made freely available. Requests for access to these data should be made to Liuwei Zhao, E-mail address: 136901672@qq.com.

\section{Conflicts of Interest}

The publication of this paper has no conflicts of interest.

\section{Acknowledgments}

This work is supported by the National Nature Science Foundation of China (nos. 71171099, 71471076, 71001028, 71201071, and 71373103) and China Scholarship Council under Grant 20123227110011.

\section{References}

[1] R. C. Savaskan, S. Bhattacharya, and L. N. Van Wassenhove, "Closed-loop supply chain models with product remanufacturing," Management Science, vol. 50, no. 2, pp. 239-252, 2004.

[2] J. D. Abbey, J. D. Blackburn, and V. D. R. Guide, "Optimal pricing for new and remanufactured products," Journal of Operations Management, vol. 36, pp. 130-146, 2015.

[3] J. D. Abbey, M. G. Meloy, V. D. R. Guide, and S. Atalay, "Remanufactured products in closed-loop supply chains for consumer goods," Production Engineering Research and Development, vol. 24, no. 3, pp. 488-503, 2015.

[4] M. P. De Brito and R. Dekker, "A Framework for Reverse Logistics," in Reverse Logistics: Quantitative Models for Closedloop Supply Chains, R. Dekker, M. Fleischmann, K. Inderfurth, and L. N. Van Wassenhove, Eds., Springer, 2004.

[5] J. Gaur, M. Amini, P. Banerjee, and R. Gupta, "Drivers of consumer purchase intentions for remanufactured products a study of Indian consumers relocated to the USA," Qualitative 
Market Research: An International Journal, vol. 18, no. 1, pp. 3047, 2015.

[6] P. Majumder and H. Groenevelt, "Competition in remanufacturing," Production Engineering Research and Development, vol. 10, no. 2, pp. 125-141, 2001.

[7] S. C. Bulmus, S. X. Zhu, and R. Teunter, "Competition for cores in remanufacturing," European Journal of Operational Research, vol. 233, no. 1, pp. 105-113, 2014.

[8] A. Örsdemir, E. Kemahlığlu-Ziya, and A. K. Parlaktürk, "Competitive quality choice and remanufacturing," Production \& Operations Management, vol. 23, no. 1, pp. 48-64, 2014.

[9] G. Juhong, H. Shuai, H. Liting et al., "Pricing and effort decisions in a closed-loop supply chain under defferent channel power structures," Journal of Cleaner Production, vol. 112, pp. 2043-2057, 2015.

[10] C. Xiaogang, Z. Benrong, and W. Hui, "CCustomer preference based decisions on price fixing and coordination in a dualchannel closed-loop supply chain," Chinese Journal of Management Science, vol. 23, no. 6, pp. 107-117, 2015.

[11] D. Vlachos, P. Georgiadis, and E. Iakovou, "A system dynamics model for dynamic capacity planning of remanufacturing in closed-loop supply chains," Computers \& Operations Research, vol. 34, no. 2, pp. 367-394, 2007.

[12] D. Hammond and P. Beullens, "Closed-loop supply chain network equilibrium under legislation," European Journal of Operational Research, vol. 183, no. 2, pp. 895-908, 2007.

[13] J.-M. Chen and C.-I. Chang, "The co-opetitive strategy of a closed-loop supply chain with remanufacturing," Transportation Research Part E: Logistics and Transportation Review, vol. 48, no. 2, pp. 387-400, 2012.

[14] Y. Guo and J. Ma, "Research on game model and complexity of retailer collecting and selling in closed-loop supply chain," Applied Mathematical Modelling: Simulation and Computation for Engineering and Environmental Systems, vol. 37, no. 7, pp. 5047-5058, 2013.

[15] W. Wenbin, D. Qingli et al., "Remanufacturing Closed-loop Supply Chain Network Equilibrium Model based on Allowance and Penalty," Operations Research and Management Science, vol. 19, no. 1, pp. 65-72, 2010.

[16] J. Changfei, C. Erbao, and L. Mingyong, "Analysis on green marketing strategy of duopoly retailing market based on the evolutionary theory," Journal of Systems Engineering, vol. 27, no. 3, pp. 383-389, 2012.

[17] C. Xiangyun, Z. Yongguang, W. Yixuan et al., "Research of lowcarbon policy to promote automotive parts remanufacturing in china: a case study of auto engine remanufacturing," Systems Engineering - Theory \& Practice, vol. 33, no. 11, pp. 2811-2821, 2013.

[18] V. D. R. Guide Jr. and L. N. van Wassenhove, "The evolution of closed-loop supply chain research," Operations Research, vol. 57, no. 1, pp. 10-18, 2009.

[19] G. D. Hatcher, W. L. Ijomah, and J. F. C. Windmill, "Design for remanufacture: A literature review and future research needs," Journal of Cleaner Production, vol. 19, no. 17-18, pp. 2004-2014, 2011.

[20] G. C. Souza, "Closed-loop supply chains: a critical review, and future research," Decision Sciences, vol. 44, no. 1, pp. 7-38, 2013.

[21] A. Tukker, M. J. Cohen, U. De Zoysa et al., "The Oslo declaration on sustainable consumption," Journal of Industrial Ecology, vol. 10, no. 1-2, pp. 9-14, 2006.
[22] S. Vercraene, J.-P. Gayon, and S. D. Flapper, "Coordination of manufacturing, remanufacturing and returns acceptance in hybrid manufacturing/remanufacturing systems," International Journal of Production Economics, vol. 148, pp. 62-70, 2014.

[23] Y. Wang, V. Wiegerinck, H. Krikke, and H. Zhang, "Understanding the purchase intention towards remanufactured product in closed-loop supply chains: An empirical study in China," International Journal of Physical Distribution and Logistics Management, vol. 43, no. 10, pp. 866-888, 2013.

[24] S. Wei, O. Tang, and E. Sundin, "Core (product) Acquisition Management for remanufacturing: a review," Journal of Remanufacturing, vol. 5, no. 4, 2015, Open access.

[25] X. Xia, K. Govindan, and Q. Zhu, "Analyzing internal barriers for automotive parts remanufacturers in China using greyDEMATEL approach," Journal of Cleaner Production, vol. 87, no. 1, pp. 811-825, 2015.

[26] J. Ma and H. Wang, "Complexity analysis of dynamic noncooperative game models for closed-loop supply chain with product recovery," Applied Mathematical Modelling: Simulation and Computation for Engineering and Environmental Systems, vol. 38, no. 23, pp. 5562-5572, 2014.

[27] L. Zhao, "Nonlinear complex dynamics of carbon emission reduction Cournot game with bounded rationality," Complexity, vol. 2017, Article ID 8301630, 7 pages, 2017.

[28] L. Zhao, "Analysis and control of the complex dynamics of a multimarket Cournot investment game with bounded rationality," Discrete Dynamics in Nature and Society, vol. 2016, Article ID 7342405, 10 pages, 2016. 


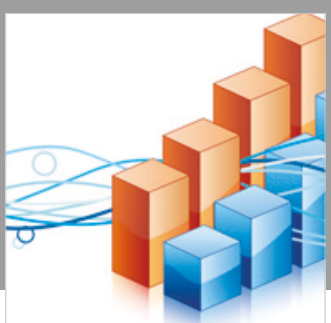

Advances in

Operations Research

\section{-n-m}
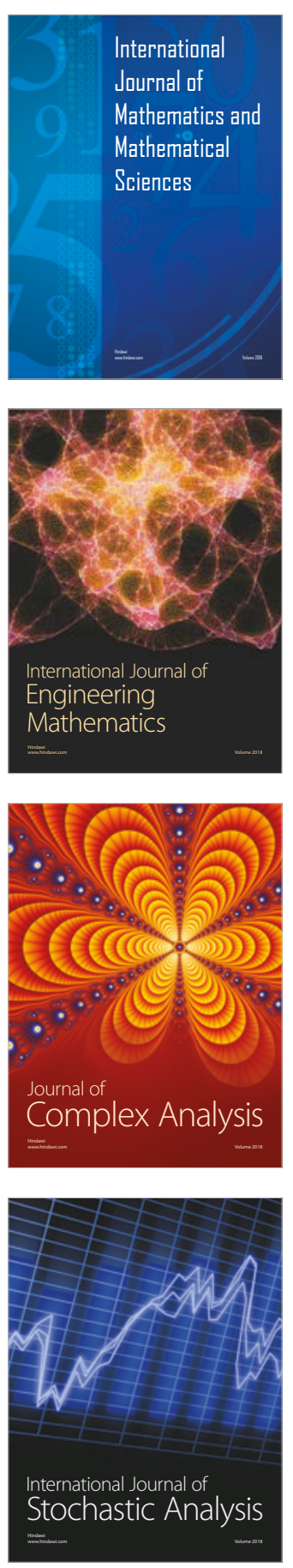
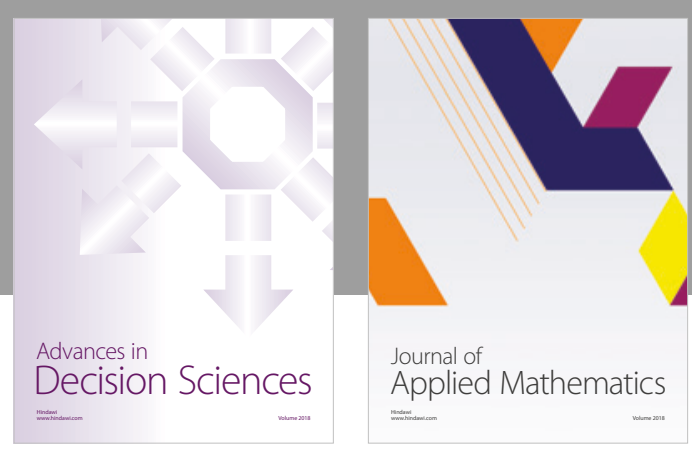

Journal of

Applied Mathematics
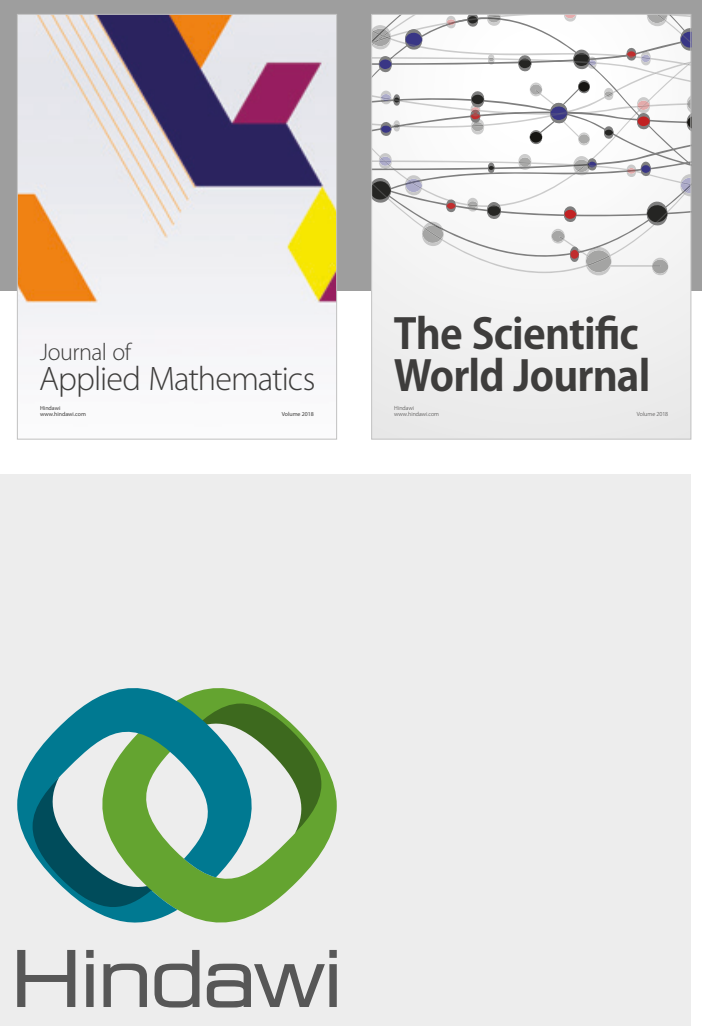

Submit your manuscripts at

www.hindawi.com

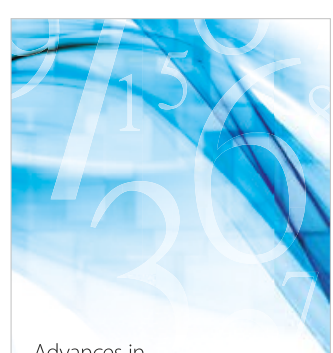

Advances in
Numerical Analysis
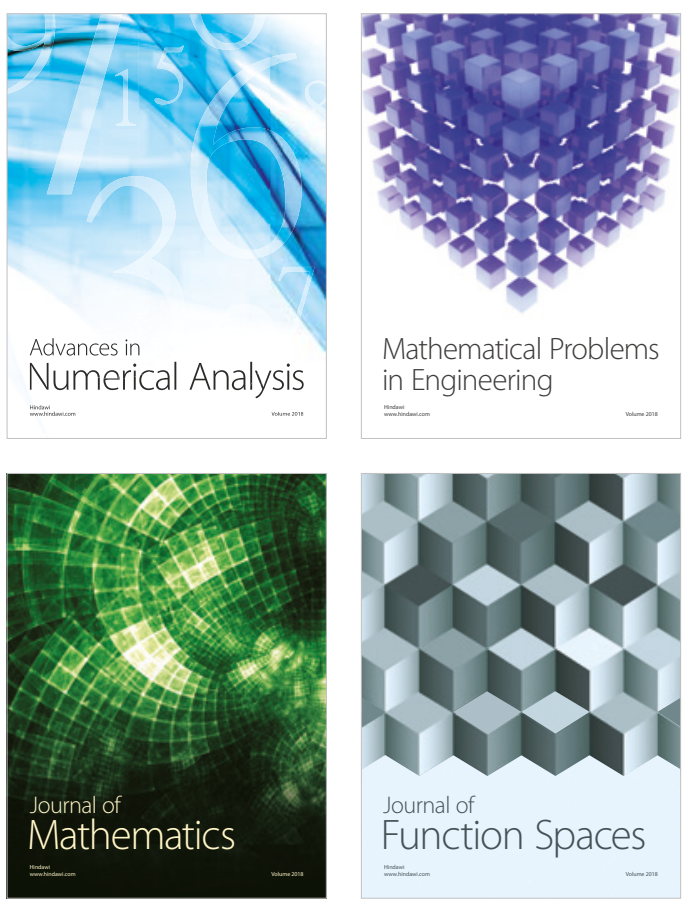

Mathematical Problems in Engineering

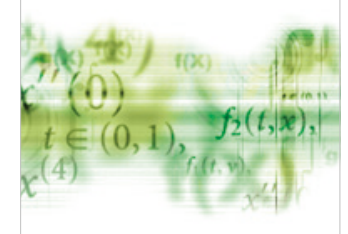

International Journal of

Differential Equations

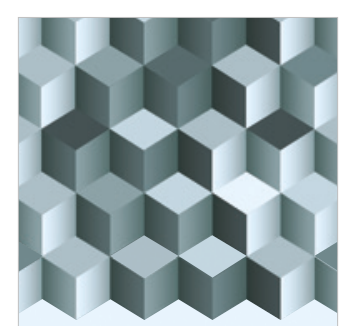

Journal of

Function Spaces

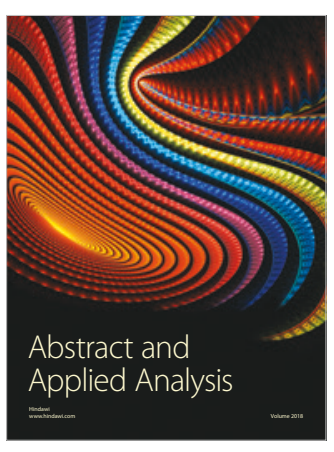

The Scientific

World Journal

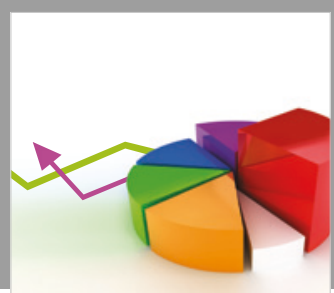

Journal of

Probability and Statistics
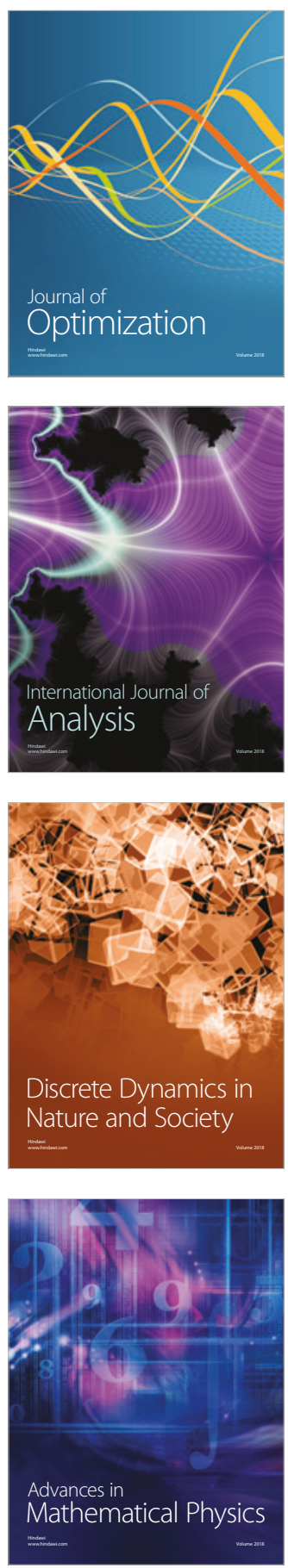